\title{
Serum miRNA profiling identifies miR-150/30a as potential biomarker for workers with damaged nerve fibers from carbon disulfide
}

\author{
Li GUO ${ }^{1 a}$, Chen $\mathrm{LUO}^{2 \mathrm{a}}$, Jingjing FAN ${ }^{2}$, Zhiguo HOU ${ }^{2}$, Xiaoming $\mathrm{JI}^{2}$, \\ Feng $\mathrm{CHEN}^{1 *}$, Baoli $\mathrm{ZHU}^{3 *}$ and Chunhui $\mathrm{NI}^{2 *}$ \\ ${ }^{1}$ Department of Epidemiology and Biostatistics, School of Public Health, Nanjing Medical University, China \\ ${ }^{2}$ Department of Occupational Medicine and Environmental Health, School of Public Health, Nanjing Medical \\ University, China \\ ${ }^{3}$ Center for Disease Control and Prevention of Jiangsu Province, China
}

Received May 28, 2014 and accepted September 2, 2014

Published online in J-STAGE September 13, 2014

\begin{abstract}
As crucial small regulatory molecules, serum microRNAs (miRNAs) have been widely identified as potential noninvasive biomarkers. To survey and identify serum miRNAs associated with workers who had experienced injury to their nerve system from carbon disulfide $\left(\mathrm{CS}_{2}\right)$, we profiled abnormally expressed miRNAs using the microarray technique and further performed qRT-PCR validation in case and control samples $(n=20)$. Microarray profiling in pooled RNA samples showed that many miRNAs in workers exposed to $\mathrm{CS}_{2}$ were aberrantly expressed. Based on control samples exposed to $\mathrm{CS}_{2}$, a great amount of abnormal miRNAs, including some miRNA gene clusters and families, were obtained from microarray datasets. Most of deregulated miRNAs were up-regulated, and almost all miRNAs showed consistent expression patterns between workers with different numbers of damaged nerve fibers. Functional enrichment analysis suggested that these abnormal miRNAs showed versatile roles by contributing to multiple biological processes. Some aberrantly expressed miRNAs were characterized as miRNA gene clusters or families, and they always showed consistent expression patterns. miR-150 and miR-30a were selected to be further validated by qRT-PCR as up-regulated species, and they could discern case samples from control samples. miR-150 and miR-30a may be potential noninvasive biomarkers for a damaged nervous system.
\end{abstract}

Key words: microRNA (miRNA), Carbon disulfide $\left(\mathrm{CS}_{2}\right)$, Biomarker

\section{Introduction}

Carbon disulfide $\left(\mathrm{CS}_{2}\right)$ can lead to damage of the nervous system and affect the blood pressure and lipid con-

\footnotetext{
${ }^{\text {a }}$ These authors contributed equally to this work.

*To whom correspondence should be addressed.

E-mail: fengchen@njmu.edu.cn; zhubl@jscdc.cn; chni@njmu.edu.cn

(C)2015 National Institute of Occupational Safety and Health
}

centration ${ }^{1)}$. A class of small non-coding RNAs (ncRNAs) and microRNAs (miRNAs) have been widely studied as crucial regulatory molecules via targeting mRNAs $^{2-4)}$. miRNAs have important roles in multiple biological processes, including cell development, cell proliferation, apoptosis and differentiation ${ }^{4,5)}$. Simultaneously, some abnormal miRNAs are also involved in pathological processes, even in tumorigenesis.

Although the small ncRNAs have been widely studied, 
Table 1. The case and control serum samples in the study

\begin{tabular}{lccccc}
\hline & Case 1 (20) & Case 2 (20) & $\begin{array}{c}\text { Control 1 (20) } \\
(\text { contact CS })\end{array}$ & $\begin{array}{c}\text { Control 2(20) } \\
\left(\text { no contact } \mathrm{CS}_{2}\right)\end{array}$ & $p$ \\
\hline Number of damaged nerve fibers & $2-5$ & 1 & 0 & 0 & \\
Age & $46.05 \pm 4.98$ & $45.45 \pm 4.70$ & $44.35 \pm 3.79$ & $46.40 \pm 5.39$ & $>0.05$ \\
Work age & $21.95 \pm 7.72$ & $21.75 \pm 6.66$ & $21.25 \pm 7.77$ & $23.55 \pm 6.83$ & $>0.05$ \\
Smoking (\%) & $12(60 \%)$ & $14(70 \%)$ & $17(85 \%)$ & $14(70 \%)$ & $>0.05$ \\
Drinking (\%) & $2(10 \%)$ & $3(15 \%)$ & $1(5 \%)$ & $4(20 \%)$ & $>0.05$ \\
Systolic pressure (mmh) & $125.95 \pm 15.25$ & $128.15 \pm 16.73$ & $122.30 \pm 15.97$ & $136.00 \pm 14.52$ & $>0.05$ \\
Diastolic pressure (mmhg) & $80.10 \pm 12.61$ & $84.20 \pm 13.75$ & $81.60 \pm 10.73$ & $91.10 \pm 12.40$ & $>0.05$ \\
\hline
\end{tabular}

The ANOVA statistical analysis ( $p$ value) is estimated.

more studies suggest that some miRNA gene families or clusters may have more versatile biological roles via coordinated regulation patterns. These related miRNAs may have various enrichment levels, but always contribute to multiple biological and pathological processes, including tumorigenesis $^{6-8)}$. A class of special miRNAs in serum tissues, termed circulating miRNAs, may be partly derived from diseased tissues and may be correlated with tumor progression. Novel potential noninvasive blood-based biomarkers have been reported because of the sensitive and informative characteristics ${ }^{9-11)}$.

Here, we attempted to survey and identify miRNAs associated with occupation exposure to $\mathrm{CS}_{2}$ in workers with damaged nerve fibers. In the study, nerve injury was estimated mainly according to the two ways: demyelination and diffuse axonal injury. The main steps were as follows: [1] serum samples were collected from workers based on the number of damaged nerve fibers (case and control samples), and control serum samples were simultaneously collected from volunteers that were not exposed to $\mathrm{CS}_{2}$ (independent control samples); [2] miRNA expression profiles in equally pooled serum samples were detected by applying the microarray technique; [3] abnormally expressed miRNAs were screened, and several of them were further identified by qRT-PCR. The study provides data for further selection of noninvasive clinical biomarkers of circulating miRNAs.

\section{Materials and Methods}

Serum samples were collected from workers exposed to $\mathrm{CS}_{2}$ with 0,1 and 2-5 damaged nerve fibers, and independent control samples were obtained from volunteers that were not exposed to $\mathrm{CS}_{2}$ (Table 1). Each group contained 20 patients or volunteers. Other factors, such as age, work age, smoking, drinking, systolic pressure and diastolic pressure were also obtained. Written informed consent was obtained from all the patients and volunteers, and the study was approved by the ethics committee of Nanjing Medical University.

The total RNA of equally pooled sample $(n=20)$ from each group was extracted using a Qiagen miRNeasy Mini kit (Qiagen, Valencia, CA, USA) according to the manufacturer's protocol. miRNA expression profiles were assessed using microarray technology (TLDA Chip, Applied Biosystems, CA, USA, V2.0). Differentially expressed miRNAs and miRNA gene clusters/families were comprehensively surveyed based on cycle threshold $(\mathrm{Ct})$ values $\left(\Delta \mathrm{C}_{\mathrm{T}}=\mathrm{C}_{\mathrm{T} \text { sample }}-\mathrm{C}_{\mathrm{T}} \mathrm{U} 6, \Delta \Delta \mathrm{C}_{\mathrm{T}}=\Delta \mathrm{C}_{\mathrm{T}}\right.$ case $-\Delta \mathrm{C}_{\mathrm{T}}$ control $)$. Experimentally validated target mRNAs of deregulated miRNAs were collected from the miRTarBase database ${ }^{12)}$. If no targets were found in the database, the integrated predicted target mRNAs were obtained using the TargetScan $\operatorname{program}^{13)}$, and Pictar ${ }^{14)}$ and miRanda programs ${ }^{15)}$. Functional enrichment was analyzed with CapitalBio Molecule Annotation System V4.0 (MAS, http://bioinfo.capitalbio. $\mathrm{com} / \mathrm{mas} 3 /)$. Clustering analysis of differentially expressed miRNAs was performed with Cluster 3.0 program and TreeView 1.60 program $^{16,17)}$ (http://rana.lbl.gov/eisen). Receiver Operating Characteristic (ROC) curves were used to evaluate the discriminating ability of selected and validated miRNAs.

Some abundantly and abnormally expressed miRNAs were also collected to be experimentally validated in 20 samples by quantitative real-time PCR (qRT-PCR). The main selection criteria were: [1] original bioinformatic analysis showed deregulated miRNAs, and these abnormally expressed miRNAs had consistent expression patterns in the two diseased groups; [2] relevant published literatures reported that selected deregulated miRNAs were associated with nerve injury by contributing to biological process in nerves system. Specifically, the total RNA of 


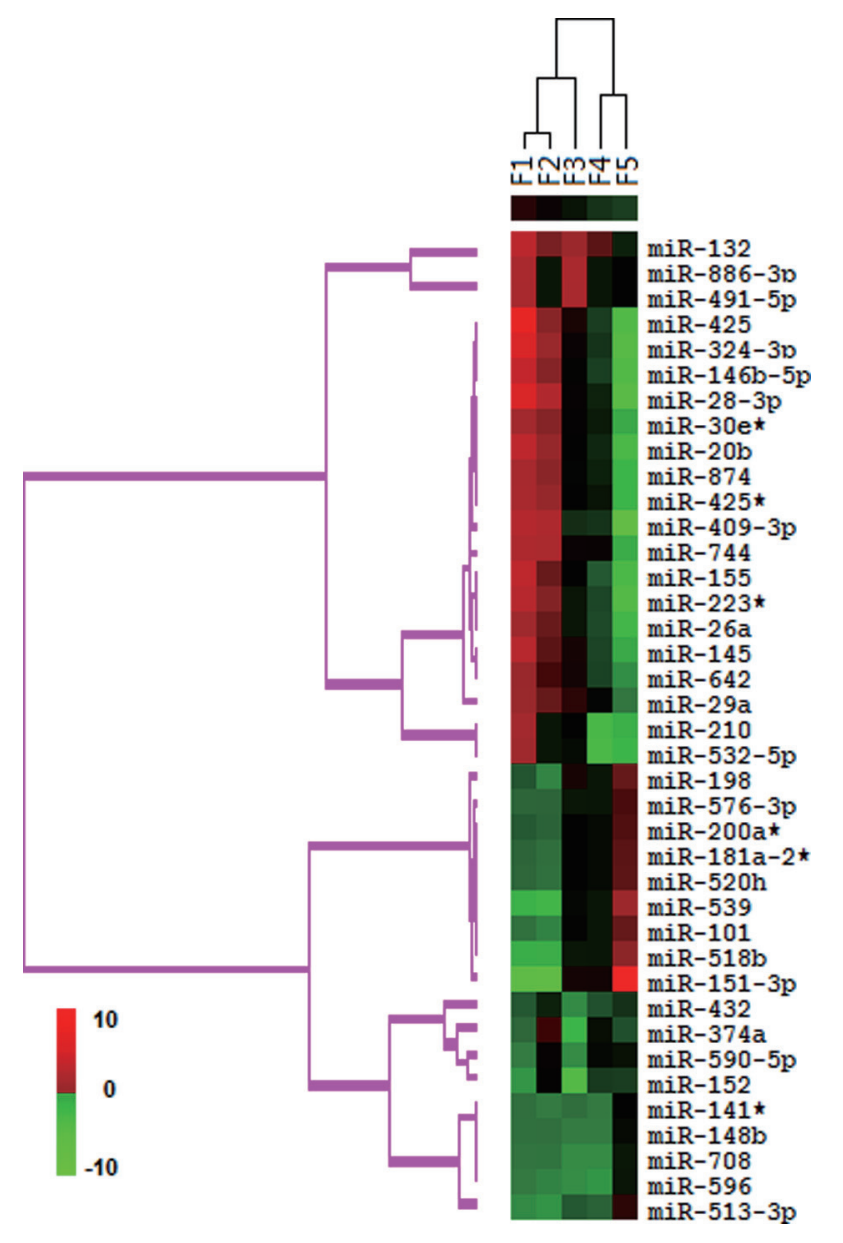

Fig. 1. A heatmap shows the top differentially expressed miRNAs between different serum samples. The fold change value is assessed

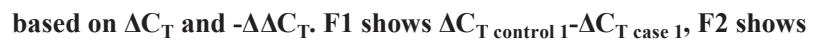

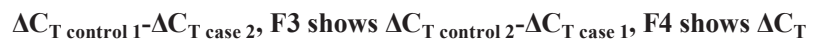
control 2- $-\Delta C_{T \text { case } 2}$, and $F 5$ shows $\Delta C_{T}$ control $2-\Delta C_{T}$ control 1

serum samples was isolated with Qiagen miRNeasy Mini kit (Qiagen, Valencia, CA, USA). According to the indicated manufacturer's instructions, the miRNA bulge-loop was reverse transcribed using the TaqMan miRNA RT Kit and stem-loop RT primers (Applied Biosystems) and quantified by qPCR using TaqMan miRNA probes (Applied Biosystems). The relative enrichment level of miRNA was normalized to snRNA U6. Averages of independent experiments each performed with standard errors were presented.

All the involved statistic analyses were performed using the Statistical Analysis System software (Version 9.1.3, SAS Institute, NC, USA) and R. $P<0.05$ was considered statistically significant, and all tests were two-tailed.
Table 2. Functional enrichment pathway analysis of aberrantly expressed miRNAs based on validated target mRNAs

\begin{tabular}{lcc}
\hline Pathway & Number of targets & $p$ value \\
\hline Pancreatic cancer & 25 & $3.57 \mathrm{E}-37$ \\
Chronic myeloid leukemia & 25 & $8.00 \mathrm{E}-37$ \\
Prostate cancer & 26 & $1.17 \mathrm{E}-36$ \\
Melanoma & 23 & $1.27 \mathrm{E}-33$ \\
Bladder cancer & 20 & $1.51 \mathrm{E}-33$ \\
Cell cycle & 26 & $8.12 \mathrm{E}-33$ \\
Colorectal cancer & 23 & $1.12 \mathrm{E}-31$ \\
Small cell lung cancer & 22 & $1.30 \mathrm{E}-29$ \\
Glioma & 20 & $7.34 \mathrm{E}-29$ \\
MAPK signaling pathway & 30 & $3.23 \mathrm{E}-28$ \\
p53 signaling pathway & 19 & $2.02 \mathrm{E}-26$ \\
Focal adhesion & 25 & $6.54 \mathrm{E}-25$ \\
Non-small cell lung cancer & 17 & $6.58 \mathrm{E}-25$ \\
Endometrial cancer & 14 & $1.22 \mathrm{E}-19$ \\
ErbB signaling pathway & 16 & $2.35 \mathrm{E}-19$ \\
Acute myeloid leukemia & 14 & $8.86 \mathrm{E}-19$ \\
Jak-STAT signaling pathway & 18 & $6.98 \mathrm{E}-18$ \\
TGF-beta signaling pathway & 15 & $8.88 \mathrm{E}-18$ \\
Adherens junction & 14 & $7.43 \mathrm{E}-17$ \\
T cell receptor signaling pathway & 15 & $3.03 \mathrm{E}-16$ \\
\hline
\end{tabular}

All of the target mRNAs can be regulated by at least 2 deregulated miRNA species

\section{Results}

No significant difference was detected for other factors between case and control samples based on ANOVA analysis (Table 1). Compared to the control 2 (not contact $\mathrm{CS}_{2}$ ), 168 miRNAs were aberrantly expressed in control 1 (contact $\mathrm{CS}_{2}$ ) (Fig. S1 and Table S1). Based on miRNA profiles of control 1 and case samples, aberrantly expressed miRNAs were assessed and obtained (Figs. 1 and S1, Table S2). Abundantly and aberrantly expressed miRNAs always showed consistent deregulated expression patterns in case samples. miR-374a was the only miRNA with opposite deregulation patterns between case 1 and case 2 (the $\log 2$ fold change values were 4.36 and -2.79 , respectively). Many abnormal miRNAs were prone to be up-regulated (Fig. 1). These deregulated species showed various expression patterns across different samples (Figs 2 and 3). Based on miRNA-mRNA interactions, these abnormal miRNAs had versatile roles in multiple biological pathways including tumorigenesis and signaling pathways (Table 2).

Of these deregulated miRNA species, some were identified as homologous or clustered miRNAs (Figs. 2 and 3). miRNA members in gene clusters and families might show 

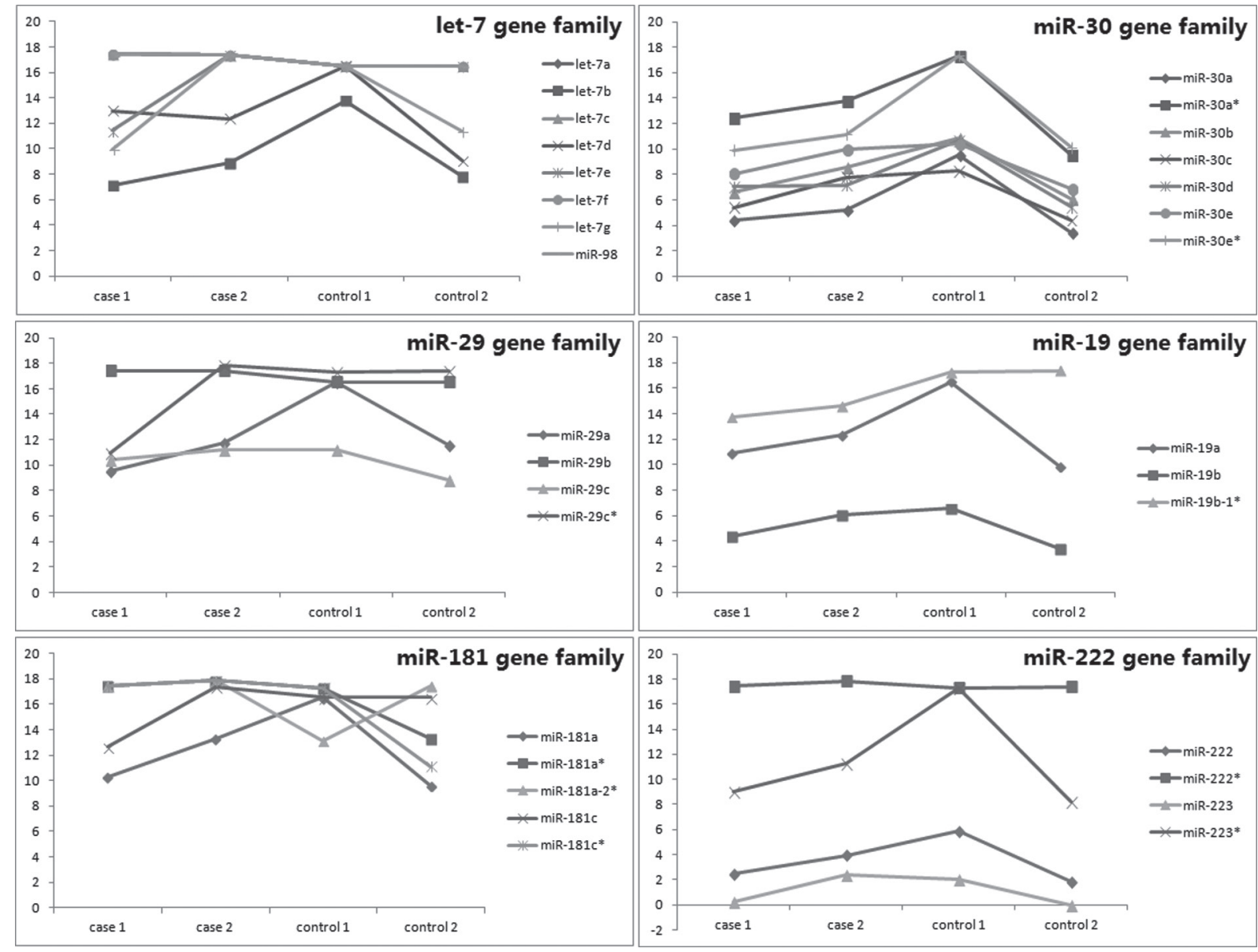

Fig. 2. The dynamic expression patterns of homologous miRNAs across different pooled serum samples based on $\Delta \mathrm{C}_{\mathrm{T}}$ (the vertical coordinates). All the homologous members in the specific miRNA gene family are presented here, although some are stably expressed. Some homologous miRNAs are also clustered in specific genomic region. The $\Delta C_{T}$ reflects the relative expression levels of miRNAs, i.e., the higher the $\Delta \mathrm{C}_{\mathrm{T}}$ value the lower the expression level.

various expression levels. Except for the stably expressed members, others always had consistent expression trends (Figs. 2 and 3). For example, the miR-19 gene family and miR-99b gene cluster were both over-expressed.

In order to screen and validate deregulated miRNA species as potential noninvasive biomarkers further, we selected miR-150/miR-30a and performed qRT-PCR validation. Compared to the control group, the two miRNAs were identified as up-regulated miRNAs ( $4-5$ folds), and they had consistent expression pattens in the two diseased groups. Both of them were identified as associated miRNAs with central nerves system ${ }^{18-21)}$. The qRT-PCR results showed similar expression patterns as observed in bioinformatics analysis (Figs. 4A). The ROC curve indicated that the two miRNAs could discern damaged nerve fibers cases from control samples (Fig. S2). These validated up-regulated miRNAs have important roles in multiple biological processes, including O-Glycan biosynthesis and Axon guidance, etc. (Fig. 4B).

\section{Discussion}

Microarray data showed a series of aberrantly expressed miRNAs, including some miRNA gene clusters and families (Tables S1 and S2, Figs. 1-3). Compared to workers that were not exposed to $\mathrm{CS}_{2}$, many miRNAs were aberrantly expressed in control 1 (Table S1). These results indicate that $\mathrm{CS}_{2}$ may directly or indirectly regulate expression levels of miRNAs. The detailed mechanisms should be derived from the toxic mechanism of $\mathrm{CS}_{2}$. For the exposed workers, almost all miRNAs have consistent up- or down-regulated expression patterns with different numbers of damaged nerve fibers (Figs. 1 and S1). Interestingly, in these differentially expressed miRNAs, the up- 


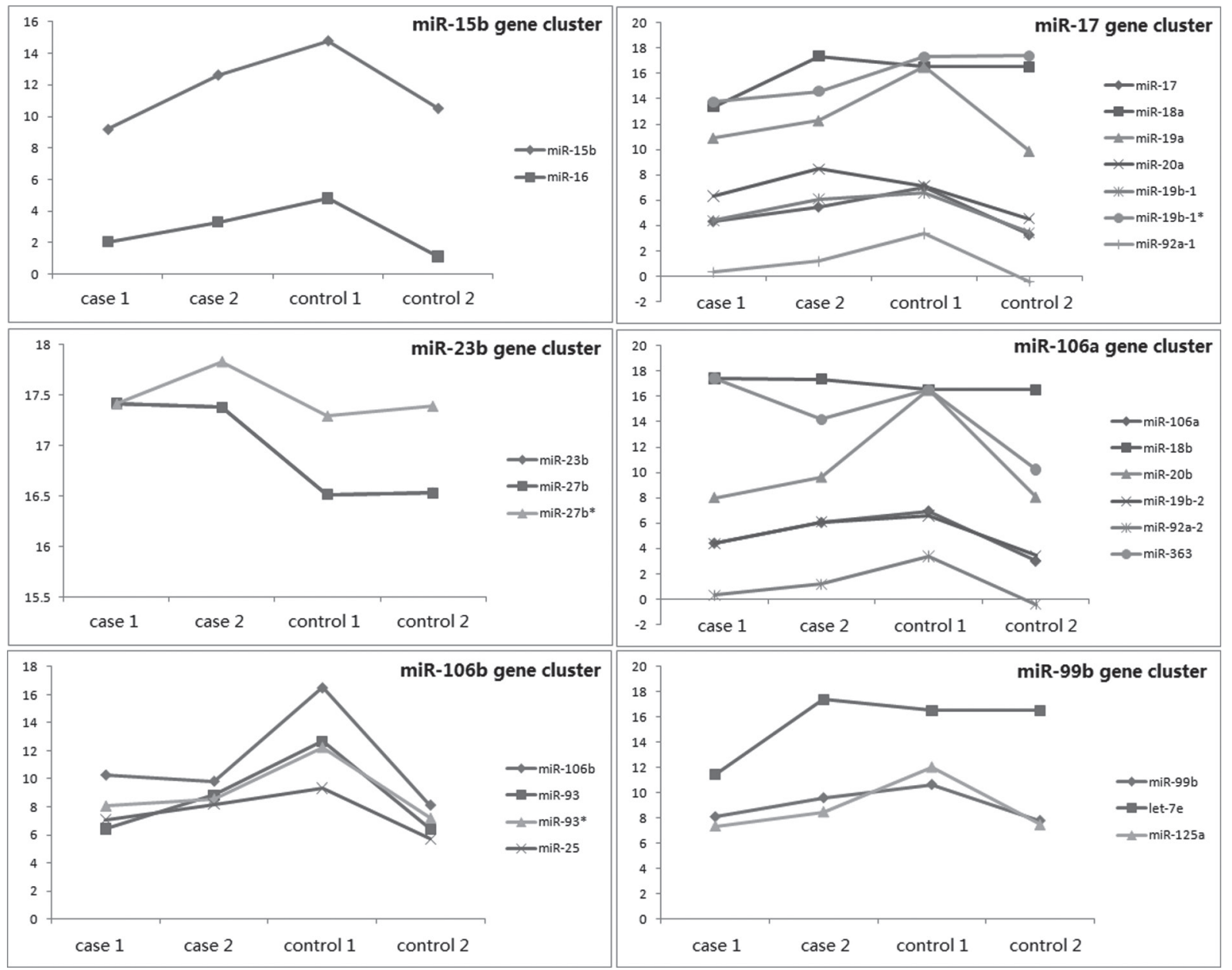

Fig. 3. The dynamic expression patterns of clustered miRNAs across different pooled serum samples based on $\Delta C_{T}$ (the vertical coordinates). All of these involved miRNAs are aberrantly expressed in case samples.

A

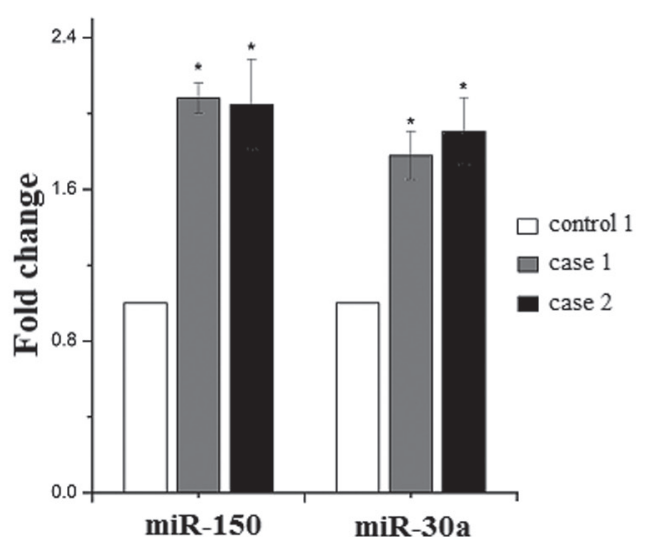

B

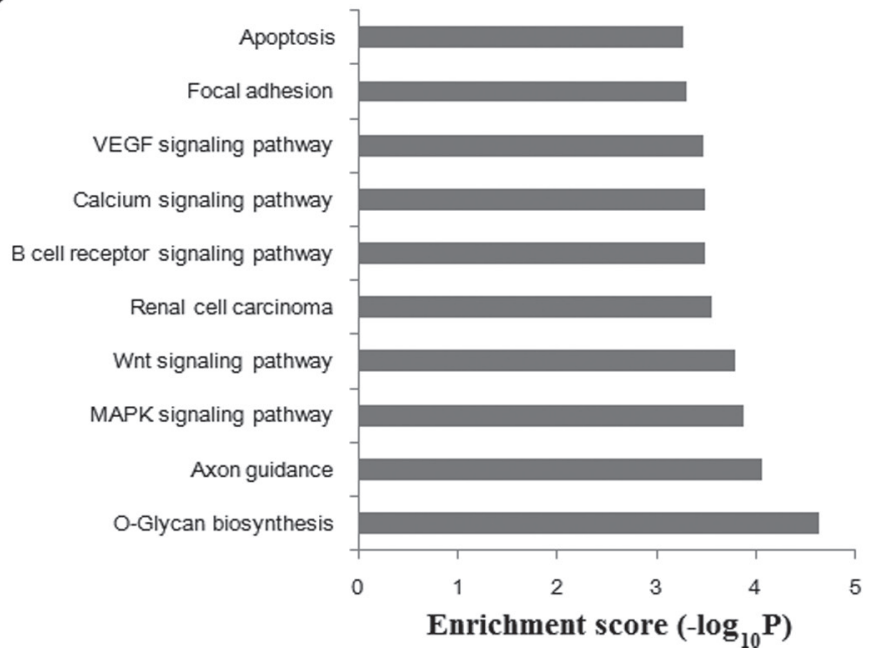

Fig. 4. qRT-PCR validation and functional enrichment analysis. (A) qRT-PCR validation; (B) functional enrichment analysis. 
regulation patterns are more popular, which indicates that potential target mRNAs are negatively regulated by these up-regulated miRNAs. Aberrant expression of mRNAs may lead to abnormal biological pathways and even pathological processes. Based on validated target mRNAs of deregulated miRNAs, the functional enrichment analysis showed that these miRNAs have important roles in multiple biological processes, including some cancers (Table 2).

Observed abnormal miRNAs may have close physical or sequence relationships, and they always are characterized as miRNA gene clusters and families (Figs. 2 and 3). These miRNAs may co-regulate multiple biological processes $^{22-24)}$, such as the versatile roles of the miR-17-92 gene cluster and family ${ }^{6-8)}$. Clustered or homologous miRNAs may have various enrichment levels in case samples, although some clustered miRNAs may be co-transcribed ${ }^{22}$, ${ }^{23,25)}$. Some members may be stably expressed, while others always show consistent aberrant expression patterns (Figs. 2 and 3). The consistent expression trends and the expression patterns may contribute to coordinated regulation between different miRNAs. The synergistic interaction further enriches the miRNA regulatory networks and miRNA-mRNA interaction. Based on the potential interaction between different miRNAs, miRNA gene clusters and families may be novel biomarkers for diagnosing diseases. The dynamic expression patterns with consistent deregulation patterns suggest their important roles in abnormal biological processes and imply their potential characters as candidate biomarkers.

Based on differentially expressed miRNAs from microarray datasets, qRT-PCR further validated up-regulated miR-150 and miR-30a in case 1, case 2 and control 1 samples ( $\mathrm{n}=20$, Figs. 4A and S2). miR-30a may function as a metastasis suppressor in metastatic colorectal carcinoma ${ }^{26)}$ and may be a tumor-suppressing miRNA in colon cancer cells ${ }^{27)}$. Indeed, another miRNA, miR-150 also has versatile biological roles. Serum miR-150 may have an important role in the pathogenesis of systemic sclerosis via regulating integrin beta $3^{28)}$. Based on experimentally validated target mRNAs, functional enrichment analysis shows that the two miRNAs have versatile roles in multiple biological pathways (Fig. 4B). The results show that $\mathrm{CS}_{2}$ can directly or indirectly lead to aberrant expression of miRNAs through the complex toxic mechanisms. These deregulated small RNAs further contribute to damage of the nervous system. As flexible small regulatory molecules, miRNAs have important roles in many biological processes, including cell development, cell proliferation, apop- tosis and differentiation ${ }^{4,5)}$. Therefore, miRNAs may be important mediums between $\mathrm{CS}_{2}$ and the damaged nervous systems and could be potential noninvasive biomarkers.

\section{Acknowledgements}

We appreciate all the patients and healthy controls who participated in this research. The work was supported by National Natural Science Foundation of China (No. 61301251, 81473070, 81072282 and 81273044), the Research Found for the Doctoral Program of Higher Education of China (No. 211323411002 and 20133234120009), China Postdoctoral Science Foundation funded project (No. 2012M521100), National Natural Science Foundation of Jiangsu (No. BK20130885), Natural Science Foundation of the Jiangsu Higher Education Institutions (No. 13KJB330003), Medicine Leading Talent and Innovation Team Project of Jiangsu Province (LJ201130), and the Priority Academic Program Development of Jiangsu Higher Education Institutions (PAPD).

\section{References}

1) Song HY, Wei CL, Dong Q, Wang ML, Ji CP, Hou ZG, Lu $\mathrm{XM}, \mathrm{Xu}$ J, Wang SY, Zhu BL, Ni CH (2012) [Studing the health status of workers occupationally exposed to carbon disulfide]. Zhonghua Lao Dong Wei Sheng Zhi Ye Bing Za Zhi 30, 443-7. [Medline]

2) Guo H, Ingolia NT, Weissman JS, Bartel DP (2010) Mammalian microRNAs predominantly act to decrease target mRNA levels. Nature 466, 835-40. [Medline] [CrossRef]

3) Huntzinger E, Izaurralde E (2011) Gene silencing by microRNAs: contributions of translational repression and mRNA decay. Nat Rev Genet 12, 99-110. [Medline] [CrossRef]

4) Bartel DP (2004) MicroRNAs: genomics, biogenesis, mechanism, and function. Cell 116, 281-97. [Medline] [CrossRef]

5) He L, Hannon GJ (2004) MicroRNAs: small RNAs with a big role in gene regulation. Nat Rev Genet 5, 522-31. [Medline] [CrossRef]

6) Bomben R, Gobessi S, Dal Bo M, Volinia S, Marconi D, Tissino E, Benedetti D, Zucchetto A, Rossi D, Gaidano G, Del Poeta G, Laurenti L, Efremov DG, Gattei V (2012) The miR-17 92 family regulates the response to Toll-like receptor 9 triggering of CLL cells with unmutated IGHV genes. Leukemia 26, 1584-93. [Medline] [CrossRef]

7) Tong MH, Mitchell DA, McGowan SD, Evanoff R, Griswold MD (2012) Two miRNA clusters, Mir-17-92 (Mirc1) and Mir-106b-25 (Mirc3), are involved in the regulation of spermatogonial differentiation in mice. Biol 
Reprod 86, 72. [Medline] [CrossRef]

8) Feuermann Y, Robinson GW, Zhu BM, Kang K, Raviv N, Yamaji D, Hennighausen L (2012) The miR-17/92 cluster is targeted by STAT5 but dispensable for mammary development. Genesis 50, 665-71. [Medline] [CrossRef]

9) Brase JC, Johannes M, Schlomm T, Fälth M, Haese A, Steuber T, Beissbarth T, Kuner R, Sültmann H (2011) Circulating miRNAs are correlated with tumor progression in prostate cancer. Int J Cancer 128, 608-16. [Medline] [CrossRef]

10) Wu X, Somlo G, Yu Y, Palomares MR, Li AX, Zhou W, Chow A, Yen Y, Rossi JJ, Gao H, Wang J, Yuan YC, Frankel P, Li S, Ashing-Giwa KT, Sun G, Wang Y, Smith R, Robinson K, Ren X, Wang SE (2012) De novo sequencing of circulating miRNAs identifies novel markers predicting clinical outcome of locally advanced breast cancer. J Transl Med 10, 42. [Medline] [CrossRef]

11) Guo L, Zhao Y, Yang S, Cai M, Wu Q, Chen F (2013) Genome-wide screen for aberrantly expressed miRNAs reveals miRNA profile signature in breast cancer. Mol Biol Rep 40, 2175-86. [Medline] [CrossRef]

12) Hsu SD, Lin FM, Wu WY, Liang $C$, Huang WC, Chan WL, Tsai WT, Chen GZ, Lee CJ, Chiu CM, Chien CH, Wu MC, Huang CY, Tsou AP, Huang HD (2011) miRTarBase: a database curates experimentally validated microRNA-target interactions. Nucleic Acids Res 39, D163-9. [Medline] [CrossRef]

13) Lewis BP, Shih IH, Jones-Rhoades MW, Bartel DP, Burge CB (2003) Prediction of mammalian microRNA targets. Cell 115, 787-98. [Medline] [CrossRef]

14) Krek A, Grün D, Poy MN, Wolf R, Rosenberg L, Epstein EJ, MacMenamin P, da Piedade I, Gunsalus KC, Stoffel M, Rajewsky N (2005) Combinatorial microRNA target predictions. Nat Genet 37, 495-500. [Medline] [CrossRef]

15) John B, Enright AJ, Aravin A, Tuschl T, Sander C, Marks DS (2004) Human MicroRNA targets. PLoS Biol 2, e363. [Medline] [CrossRef]

16) Eisen MB, Spellman PT, Brown PO, Botstein D (1998) Cluster analysis and display of genome-wide expression patterns. Proc Natl Acad Sci USA 95, 14863-8. [Medline] [CrossRef]

17) Chiang DY, Brown PO, Eisen MB (2001) Visualizing associations between genome sequences and gene expression data using genome-mean expression profiles. Bioinformatics 17 Suppl 1, S49-55. [Medline] [CrossRef]

18) Wang P, Liang J, Li Y, Li J, Yang $X$, Zhang $X$, Han S, Li S, Li J (2014) Down-regulation of miRNA-30a alleviates cerebral ischemic injury through enhancing beclin 1-mediated autophagy. Neurochem Res 39, 1279-91.
[Medline] [CrossRef]

19) Croce N, Gelfo F, Ciotti MT, Federici G, Caltagirone C, Bernardini S, Angelucci F (2013) NPY modulates miR-30a$5 \mathrm{p}$ and BDNF in opposite direction in an in vitro model of Alzheimer disease: a possible role in neuroprotection? Mol Cell Biochem 376, 189-95. [Medline] [CrossRef]

20) Jia Z, Wang K, Wang G, Zhang A, Pu P (2013) MiR-30a$5 p$ antisense oligonucleotide suppresses glioma cell growth by targeting SEPT7. PLoS ONE 8, e55008. [Medline] [CrossRef]

21) Yang C, Wang C, Chen X, Chen S, Zhang Y, Zhi F, Wang J, Li L, Zhou X, Li N, Pan H, Zhang J, Zen K, Zhang CY, Zhang C (2013) Identification of seven serum microRNAs from a genome-wide serum microRNA expression profile as potential noninvasive biomarkers for malignant astrocytomas. Int J Cancer 132, 116-27. [Medline] [CrossRef]

22) Lim LP, Glasner ME, Yekta S, Burge CB, Bartel DP (2003) Vertebrate microRNA genes. Science 299, 1540-1540. [Medline] [CrossRef]

23) Xu JZ, Wong CW (2008) A computational screen for mouse signaling pathways targeted by microRNA clusters. RNA 14, 1276-1283.

24) Diosdado B, van de Wiel MA, Terhaar Sive Droste JS, Mongera S, Postma C, Meijerink WJHJ, Carvalho B, Meijer GA (2009) MiR-17-92 cluster is associated with $13 \mathrm{q}$ gain and c-myc expression during colorectal adenoma to adenocarcinoma progression. Br J Cancer 101, 707-14. [Medline] [CrossRef]

25) agos-Quintana M, Rauhut R, Meyer J, Borkhardt A, Tuschl T, (2003) New microRNAs from mouse and human. RNA 9, 175-179.

26) Zhong M, Bian Z, Wu Z (2013) miR-30a suppresses cell migration and invasion through downregulation of PIK3CD in colorectal carcinoma. Cell Physiol Biochem 31, 209-18. [Medline] [CrossRef]

27) Baraniskin A, Birkenkamp-Demtroder K, Maghnouj A, Zöllner H, Munding J, Klein-Scory S, Reinacher-Schick A, Schwarte-Waldhoff I, Schmiegel W, Hahn SA (2012) MiR-30a-5p suppresses tumor growth in colon carcinoma by targeting DTL. Carcinogenesis 33, 732-9. [Medline] [CrossRef]

28) Honda N, Jinnin M, Kira-Etoh T, Makino K, Kajihara I, Makino T, Fukushima S, Inoue Y, Okamoto Y, Hasegawa M, Fujimoto M, Ihn H (2013) miR-150 downregulation contributes to the constitutive type I collagen overexpression in scleroderma dermal fibroblasts via the induction of integrin $\beta 3$. Am J Pathol 182, 206-16. [Medline] [CrossRef] 


\section{Appendix}

Table S1. The top 10 up- and down-regulated miRNA species in control 1

\begin{tabular}{lccc}
\hline Up-regulated miRNAs & FC (abs) & Down-regulated miRNAs & FC (abs) \\
\hline miR-151-3p & $1,621.37$ & miR-409-3p & 1026.13 \\
miR-539 & 140.75 & miR-28-3p & 676.99 \\
miR-518b & 91.27 & miR-324-3p & 582.45 \\
miR-433 & 32.49 & miR-223* & 535.60 \\
miR-198 & 26.46 & miR-146b-5p & 478.04 \\
miR-101 & 25.79 & miR-425 & 465.62 \\
miR-520h & 20.15 & miR-155 & 386.68 \\
miR-181a-2* & 19.20 & miR-20b & 356.07 \\
miR-200a* & 13.75 & miR-106b & 342.75 \\
miR-769-5p & 12.54 & miR-10b* & 333.61 \\
\hline
\end{tabular}

These deregulated miRNA species are assessed using absolute fold change (abs) based on control 2 .

Table S2. The top 10 up- and down-regulated miRNA species

\begin{tabular}{clcc}
\hline Up-regulated miRNAs & \multicolumn{1}{c}{ FC $($ abs $)$} & Down-regulated miRNAs & FC (abs) \\
\hline miR-425 & $1,105.13,76.16$ & miR-151-3p & $829.44,871.28$ \\
miR-324-3p & $805.64,127.56$ & miR-539 & $181.90,253.88$ \\
miR-28-3p & $800.63,253.53$ & miR-518b & $169.13,164.62$ \\
miR-146b-5p & $436.85,72.86$ & miR-152 & $80.39,0.91$ \\
miR-155 & $376.11,28.78$ & miR-513-3p & $56.61,75.58$ \\
miR-20b & $363.04,117.87$ & miR-590-5p & $36.45,0.83$ \\
miR-132 & $333.14,47.87$ & miR-596 & $35.33,47.18$ \\
miR-223* & $300.25,67.00$ & miR-708 & $30.93,30.11$ \\
miR-145 & $297.14,19.31$ & miR-101 & $28.40,46.53$ \\
miR-409-3p & $274.18,221.48$ & miR-148b & $27.83,27.10$ \\
\hline
\end{tabular}

These deregulated miRNA species are assessed based on absolute fold change (abs). The top 10 miRNAs were collected based on case 1 with 2-5 damaged nerve fibers. The abs values of case 2 were also presented. 
A

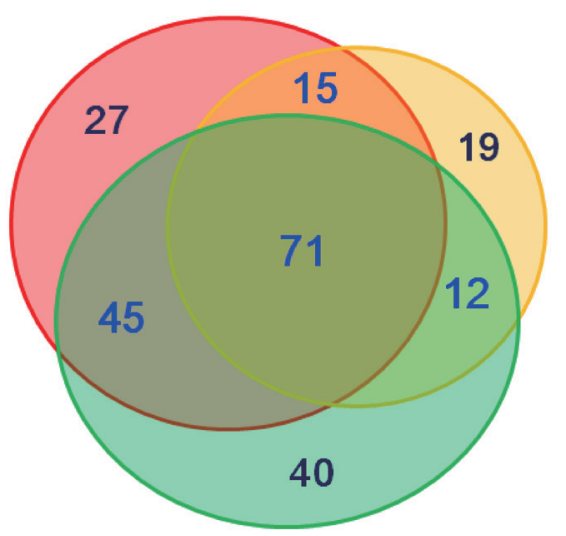

Case $1 /$ control 1

Case 2/control1

Control1/control2

B

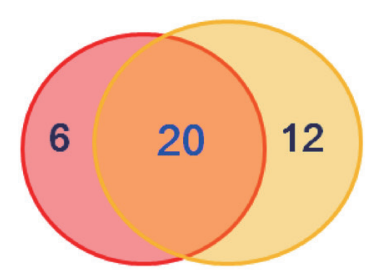

C

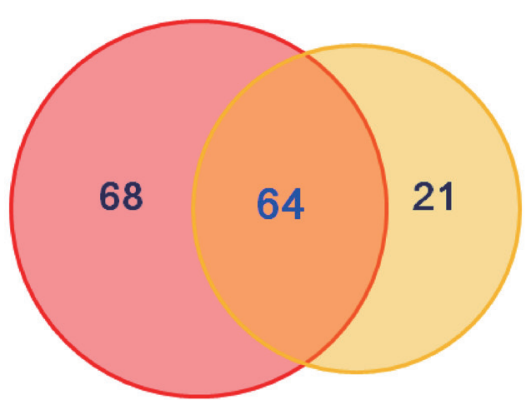

Fig. S1. The number distributions of deregulated miRNA species in case 1 and case 2 (based on control 1), and control 1 (based on control 2). (A) Number of significantly up-regulated and down-regulated miRNAs between case 1, case 2 and control 1; (B) Number of down-regulated miRNA species between case 1 and case 2; (C) Number of up-regulated miRNA species between case 1 and case 2. 
A

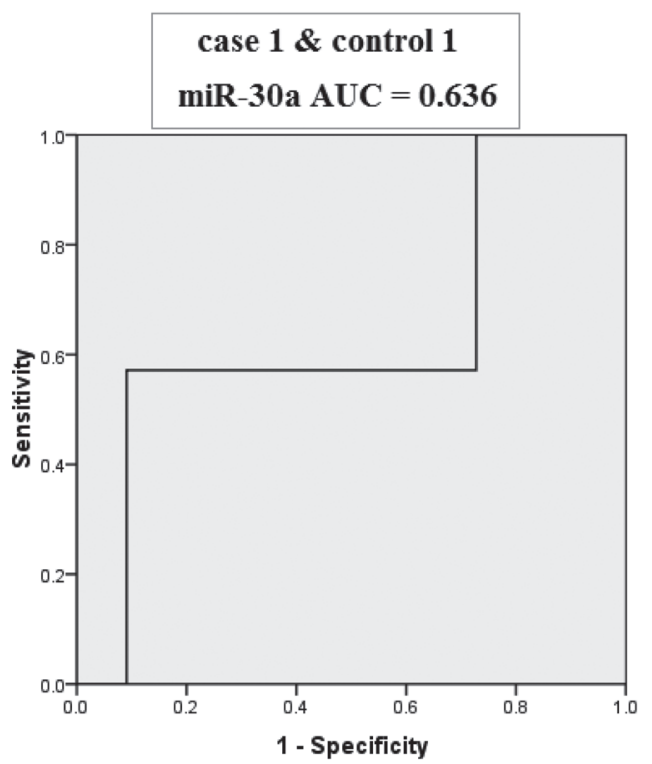

C

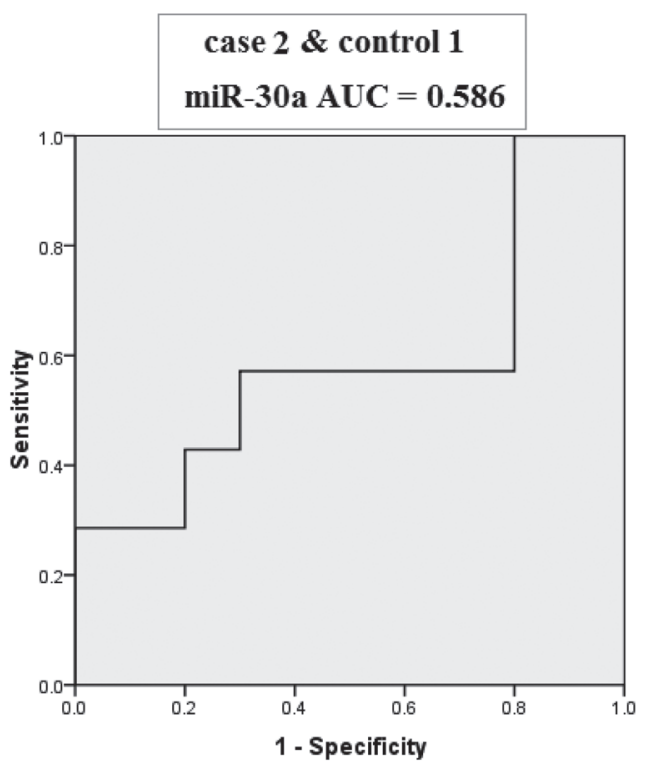

B

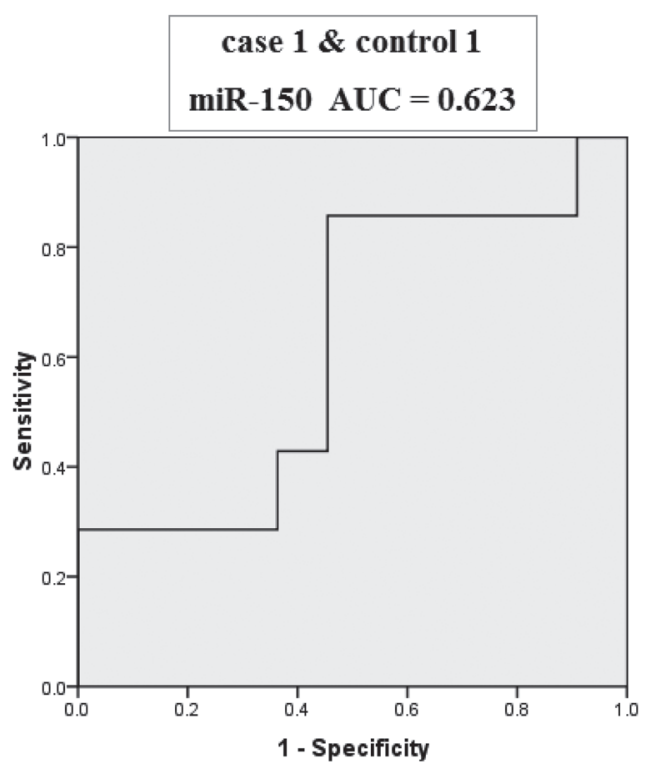

D

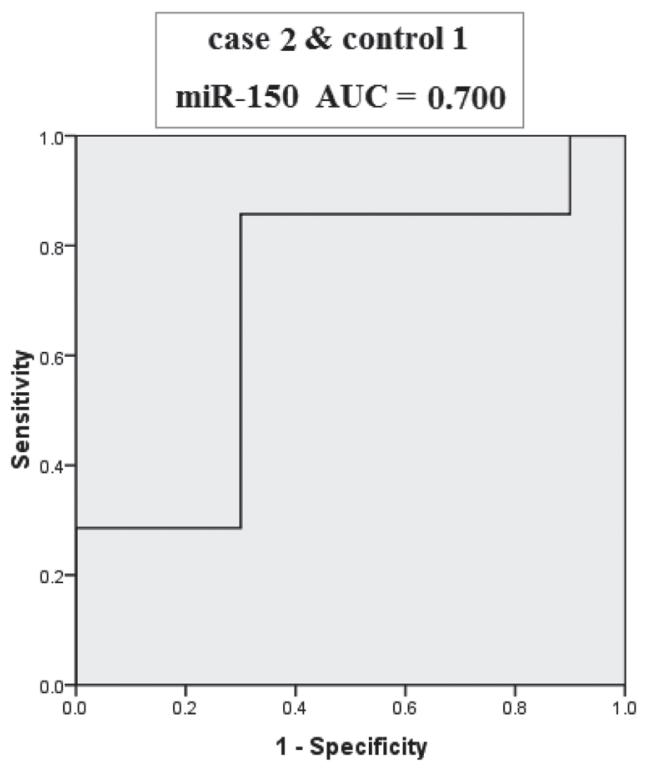

Fig. S2. ROC curve analysis for discrimination between case 1 , case 2 and control 1 samples by the miR-150 and miR-30a. 